\title{
Types of Predication in Aristotle (Posterior Analytics I 22)
}

\author{
António Pedro Mesquita
}

Predication is a complex entity in Aristotelian thought. The aim of the present essay is to account for this complexity, making explicit the diverse forms it assumes. To this end, we turn to a crucial chapter of the Posterior Analytics (1 22), where, in the most complete and developed manner within the corpus, Aristotle proceeds to systematize this topic. From the analysis, it will become apparent that predication can assume,

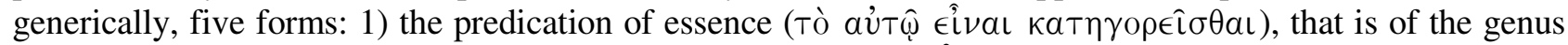

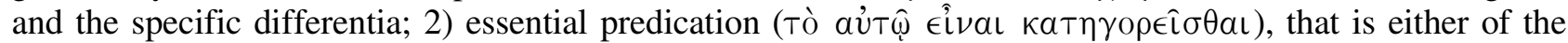
genus or of the differentiae (or their genera); 3) the predication of accidents per se; 4) the predication of

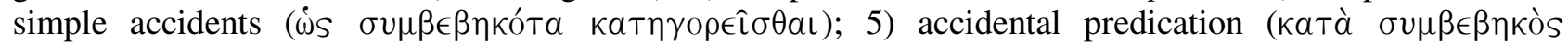

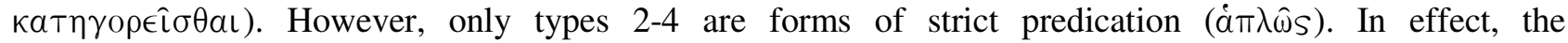
"predication" of essence is not a genuine predication, but a formula for identity, constituting, technically, the statement of the essence of the subject (or its definition). On the other hand, accidental "predication" can only be conceived of as such equivocally, since it results from a linguistic accident through which the ontological subject of the attribution suffers a displacement to the syntactic position of the predicate, which is not, by nature, its own. In neither case does the phrase bring about any legitimate predication. The study concludes with a discussion of Aristotle's thesis according to which no substance can be a predicate, which is implied by its notion of accidental predication, a thesis which has been - and in our opinion wrongly so challenged in modern times.

Predication is a complex entity in Aristotle's thought. The object of the present paper is to account for that complexity, rendering explicit the several forms it assumes. Given the significance of this concept in Aristotle's logic and ontology, the task is relevant per se. It is, however, particularly important to avoid the confusion that can easily set in between two concept pairs whose

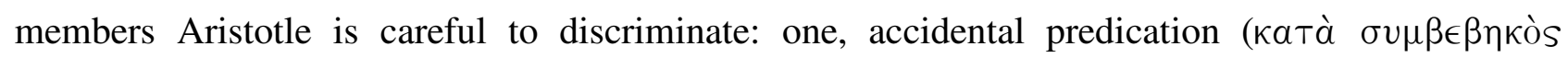

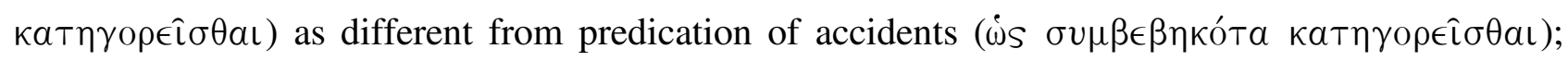
the other, essential predication (

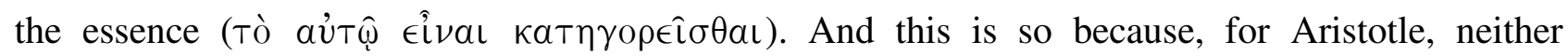
accidental predication nor predication of the essence is, strictly speaking, predication, but rather the "lower" and "upper" margins within whose scope predication is defined. 
Journal of Ancient Philosophy Vol. VI 2012 Issue 2

The "upper" limit - predication of the essence - is definition. The distinction between definition and approximate forms of predication (viz., essential predication) is crucial to set up a precise distinction between predication and definition and to understand the singularity the notion of definition holds within the set of attributive statements in Aristotle. The "lower" limit

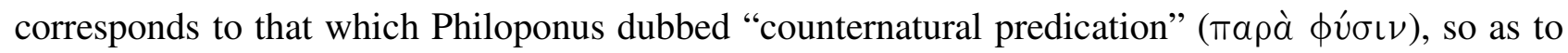

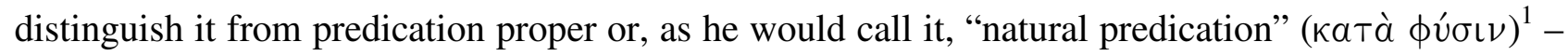
clearly, a heavily symbolic classification.

It is in a crucial chapter of the Posterior Analytics (I 22), a chapter which apparent purpose is merely to show the impossibility of an infinite chain of premises in demonstration, that Aristotle will present, in a thorough and systematic manner, a schematisation of the various types of predication. Accordingly, it will be by addressing this chapter, in the form of a running commentary on each of its significant units, that we will attempt to follow Aristotle's lesson on this issue.

\section{Strict Predication and Accidental Predication}

\section{Text: ${ }^{2}$}

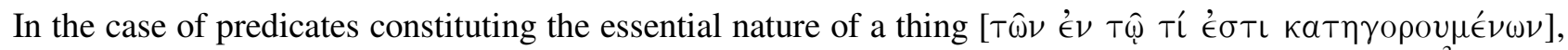
the situation is clear: if definition is possible, or, in other words, if essential form is knowable, ${ }^{3}$ and an

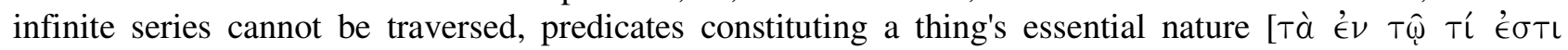
$\kappa \alpha \tau \eta \gamma о \rho о \cup ́ \mu \in \nu \alpha]$ must be finite in number. But as regards predicates generally we have the following prefatory remarks to make. We can affirm without falsehood that the white (thing) is walking and that that big (thing) is a log; or again, that the log is big and that the man walks. But the affirmation differs in the two cases. When I affirm that the white is a log, I mean that something which happens to be white is a $\log$ [öTı $\hat{\dot{\varphi}}$

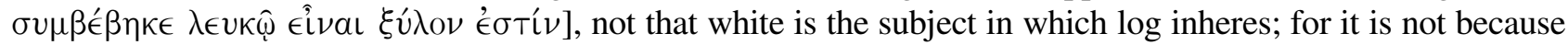
it is white or precisely a certain type of white [oй $\delta^{\prime}$ ö $\left.\pi \epsilon \rho \lambda \epsilon \cup \kappa o ́ v \tau \iota\right]$ that the white (thing) comes to be a log. Therefore, the white (thing) is not a log except incidentally [literally, by accident:

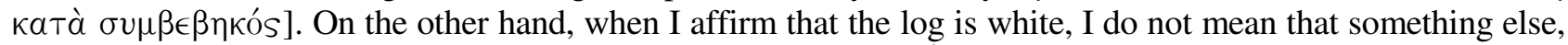

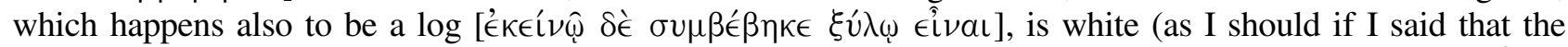

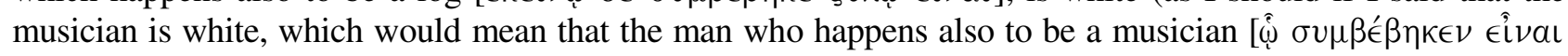

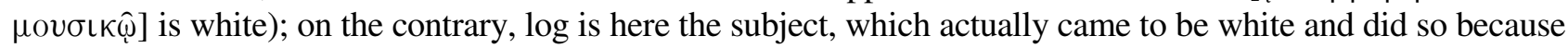
it is a $\log$ or precisely a certain $\log$, not because it is something else. If, then, we must lay down a rule, let us

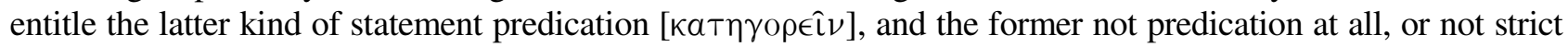

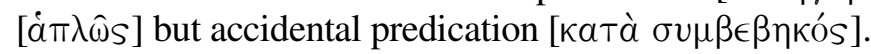

1 Cf. In APo. 236.24-26 Wallies.

2 APo. I 22, 82b37-83a17. (All translations of this chapter are Mure's, with corrections.)

3 Here, the conjunction $\eta^{\prime}$ clearly holds epexegetic, not disjunctive, value (thus Mure, Tredennick, Tricot). 
Journal of Ancient Philosophy Vol. VI 2012 Issue 2

\section{Comment:}

In these two paragraphs, Aristotle drafts a preliminary enumeration of several types of predication: essential predication; ${ }^{4}$ predication proper, or strict predication; ${ }^{5}$ and accidental predication. ${ }^{6}$ Strict predication $(\dot{\alpha} \pi \lambda \omega \hat{\omega})^{7}$ and accidental predication $(\kappa \alpha \tau \grave{\alpha} \quad \sigma \nu \mu \beta \epsilon \beta \eta \kappa o ́ s)^{8}$ are clearly distinguished at the end of the passage as opposite types of predication. The text is, at this point, particularly interesting. The distinction between accidental and strict predication is there made to depend on a metaphysical interpretation of the subject/predicate pair, namely, that not every object that can fill the predicate's logical or syntactic slot in a sentence is a predicate in the ontological sense, and particularly the actual predicate of the sentence's subject, that is, something that actually belongs to it. A more basic distinction is here being assumed between that which is a predicate by nature, i.e., that which is said of something (of a "natural" subject), and that which is a subject by nature, i.e., that of which something (a "natural" predicate) is said.

Aristotle's thesis that no individual (or, in the terms of the Categories, no primary substance) can be a predicate is here justified. What it states is that every individual is "naturally" a subject, for which reason it cannot be (from an ontological point a view) a predicate. When an individual comes to be a predicate (from a logical or syntactic point of view), which is to say, when it happens that the name of an individual, or, in general, a singular term, fills the predicative slot in an attributive sentence, this happens in a merely accidental way, i.e., by virtue of a linguistic accident that abusively shifts it to that inappropriate slot. ${ }^{9}$ Now, this is the assumption that justifies the distinction between strict predication (where subject and predicate are "natural") and accidental predication, where subject (e.g., musician in "The musician is white") or both subject and predicate (e.g.,

\footnotetext{
4 82b37-83a1.

5 83a9-14.

$683 a 4-9$.

$783 \mathrm{a} 16$.

8 83a16-17.
}

9 See, typically, APr. I 27, 43a32-36: "It is clear then that certain things are not naturally said of anything

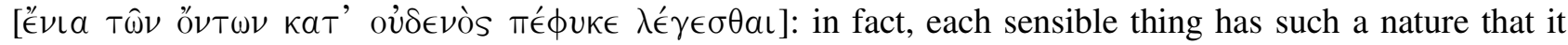

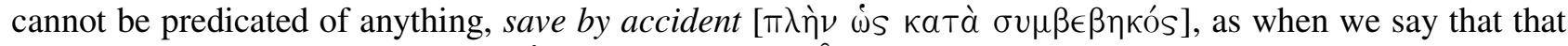

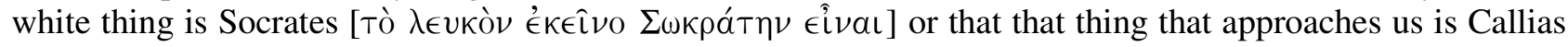

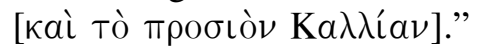


Journal of Ancient Philosophy Vol. VI 2012 Issue 2

"That white thing is a log") are not "natural". ${ }^{10}$ We can thus say that, concerning the distinction between these two types of predication, the late neo-Platonic nomenclature that dubbed them "natural" and "counternatural", respectively, albeit not introduced by the Stagirite, quite aptly reflects the spirit of his doctrine in this regard.

It is worth pointing out that the relation of either one or both types of predication to the essential predication mentioned in the first paragraph is nowhere clarified. Furthermore, it is not explicit whether such predication should be included under strict predication or, on the contrary, whether it should be understood as some autonomous type to which the two other types of predication distinguished in the second paragraph would jointly oppose. In this circumstance, the table resulting from the two initial paragraphs can be, quite simply, as follows:

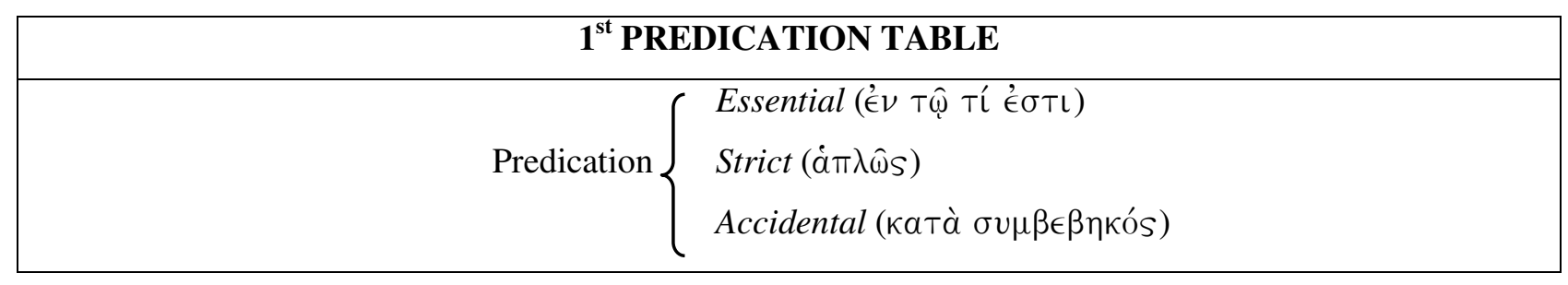

However, given that all examples added in the second paragraph are examples of non-essential predication, one could assume that the distinction Aristotle introduced therein between strict predication and accidental predication is not to be added to the type mentioned in the first paragraph, but to oppose to it, which would entail reformulating the table thus:

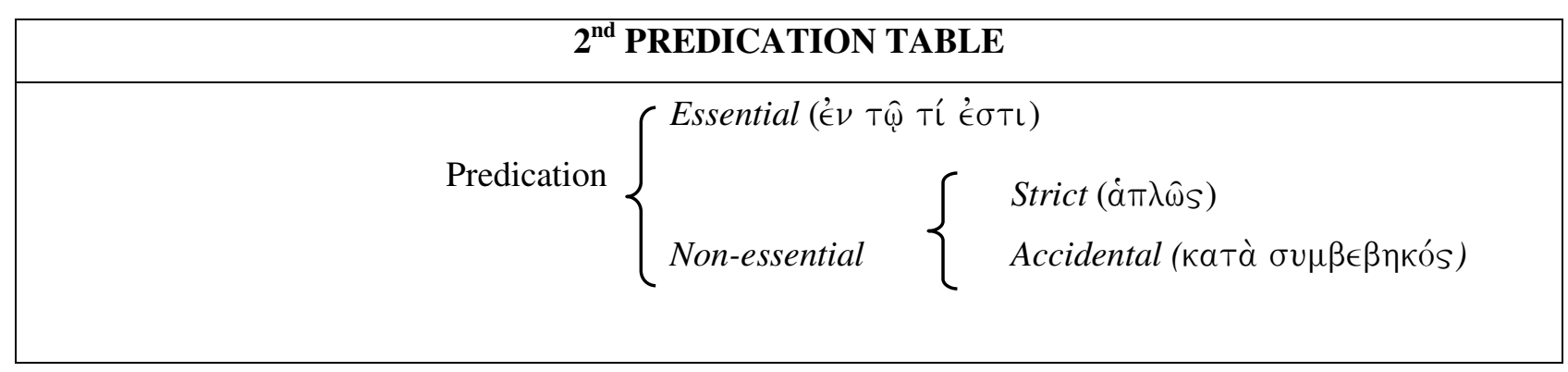

${ }^{10}$ Along the same lines, cf. Metaph. $\triangle$ 7, 1017a7-22, and also: Int. 11, 21a7-16; APr. I 27, 43a32-43; APo. I 4, 73b5-10; APo. I 19, 81b23-29. Other scattered occurrences in: APo. I 13, 79a6; Ph. I 4, 188a8; Metaph. A 6, 987b23; B 4, 1001a6; 1001a10; 1001a 28; N 1, 1087a33; 1087a 35; 1088a28. 
Journal of Ancient Philosophy Vol. VI 2012 Issue 2

This is why the differentiation between strict and accidental predications opens the subsequent text, which is aimed at excluding the latter, but not the former, from the discussion.

\section{Strict Predication}

Text: ${ }^{12}$

White and log will thus serve as types respectively of predicate and subject. We shall assume, then, that the

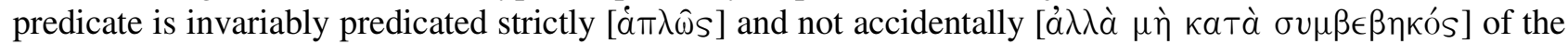
subject, for on such predication demonstrations depend for their force. It follows from this that when a single attribute is predicated of a single subject, the predicate must affirm of the subject either some element constituting its essential nature $\left[\hat{\eta} e^{\prime} \nu \tau \hat{\varphi} \tau \tau^{\prime} \dot{\epsilon} \sigma \tau L \nu\right]$, or that it is in some way qualified, quantified, related, active, passive, placed, or dated.

\section{Comment:}

The content of the present paragraph can be captured in the following theses:

1) In every predicative sentence, a predicate stands in the same relation to the subject as 'B' stands to ' $\mathrm{A}$ ' in the standard sentence 'A is B'.

2) The predicate can be predicated of the subject either strictly or accidentally.

3) In canonical, or strict, predicative sentences, the predicate stands in the same relation to the subject as "white" stands to "log" in the sentence "The log is white". (Up to this point, we have merely summed up the doctrine accounted for in the previous paragraph.)

4) Now, every strict predication abides by the table of categories; therefore, in such predication, the predicate says of the subject either what the subject is, or of which type it is, or how many it is, or in relation to what it is, etc. ${ }^{13}$

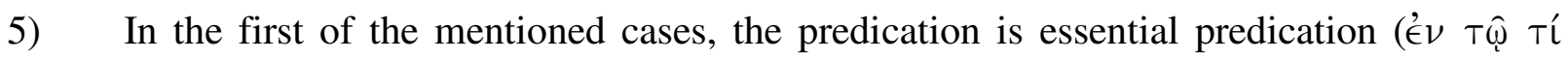

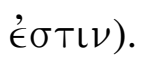

6) In all remaining cases, it will certainly be strict, but not essential, predication.

\footnotetext{
${ }^{12}$ APo. I 22, 83a17-23.

${ }^{13}$ This theme, a highly central one in Aristotelian logic and ontology, could not even begin to be summarised within the scope of the current essay. We thus refer the reader to the corresponding chapter in our Introdução Geral, pp. 489-495.
} 
Journal of Ancient Philosophy Vol. VI 2012 Issue 2

The consequences of this clarification for our subject matter, particularly for solving the problem left suspended in section 1, are evident. Following this clarification, strict predication is the predication type that can be essential or non-essential, in which case the former is rehabilitated (and given the same status as the latter) as a type of strict predication. We may now use the data from the current paragraph to put forward a third predication table:

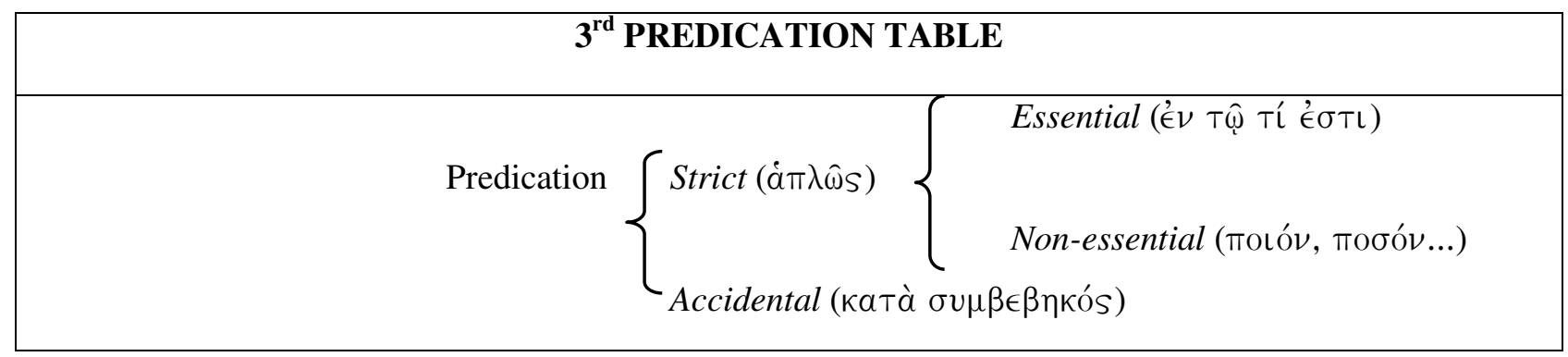

There is a staggering difference between the second and third tables:
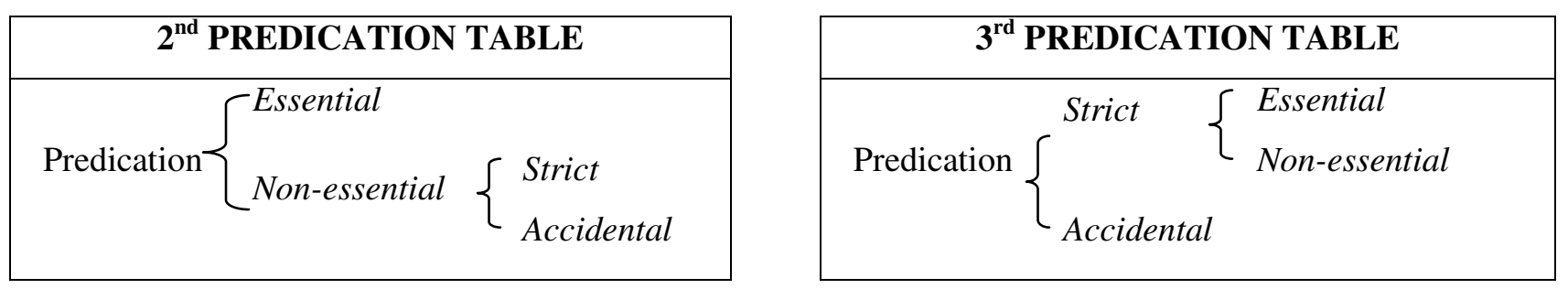

In the left-hand side table, essential predication is opposed to both strict predication and accidental predication, which are here presented as two types of non-essential predication. In the right-hand side table, essential predication is placed under strict predication, and it is the latter which, in both its variants (essential predication and non-essential predication), is now opposed to non-strict, or accidental, predication. Clearly, the point of contrast concerns which locus to attribute to essential predication. Before such a huge discrepancy between the two doctrines, to which should we ascribe greater value? Should essential predication be considered a sub-type of strict predication (third table) or, on the contrary, it is to stand as a predication type, side-by-side with non-essential (strict and accidental) predication (second table)? This can only be decided in light of the information provided in the subsequent paragraphs. 
Journal of Ancient Philosophy Vol. VI 2012 Issue 2

\section{Strict Predication (a) of the Substance and (b) of Accidents}

Text: ${ }^{14}$

Predicates which signify substance signify precisely the subject, or a certain type of the subject. Predicates not signifying substance which are predicated of a subject which is neither precisely what the subject is, nor a certain type of what the subject is, are accidents $[\sigma v \mu \beta \in \beta \eta \kappa o ́ \tau \alpha]$. For instance, when you predicate white

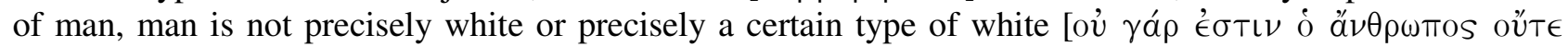

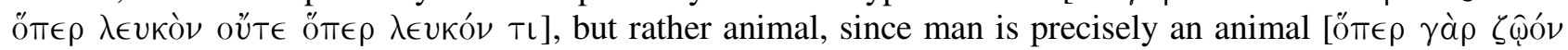
$\dot{\epsilon} \sigma \tau L \nu \dot{o} a ̈ \nu \theta \rho \omega \pi \mathrm{s}]$. These predicates which do not signify substance must be predicates of some other subject, and nothing can be white which is not white because of something else.

\section{Comment:}

In this paragraph, Aristotle sets forth a double alternative to what we have so far been indistinctly calling "essential predication". On the one hand, some essential predicates (or "things which signify substance") are those that "signify precisely the subject". Under this usage, essential predicates express the subject itself and therefore, as far as predication is concerned, the predicate is identical to the subject. ${ }^{15}$ On the other hand, essential predicates can also be those that signify "a certain type of what the subject is". In this instance, essential predicates do not express the subject itself, but that under which the subject falls in the generative scale, namely, a genus, or a differentia of the subject. ${ }^{16}$

Considering the alternative here proposed, we may now understand that essential predication in a certain sense is and in a certain sense is not strict predication, which allows us to understand the reason for the discrepancy between the second and third tables, as well as to solve it, bringing it to a more enlightening compatibility.

In a certain sense it is, and in another sense it is not, strict predication, because it itself already has two meanings, namely, those two we have just introduced. Let us be quite clear, though, as to what this means. It is not that, in Aristotle, the present sentence on the one hand excludes, while on the other hand includes, essential predication from strict predication. In fact, from Aristotle's point

\footnotetext{
${ }^{14}$ APo. I 22, 83a24-32.

${ }^{15}$ In Aristotle, the terms "identical", "identification", "identity", which we will henceforth systematically use, always possess intensional value, expressing the interchangeability of the subject and the predicate and not just their simple co-extensionality. Technically speaking, in Aristotle, the latter constitutes predication proper, whilst the former is the definition (cf. Topics I 4-5, 8).

${ }^{16}$ Cf. 83b1.
} 
Journal of Ancient Philosophy Vol. VI 2012 Issue 2

of view, the characterisation of essential predication here introduced is stated against non-essential predication and within the general framework of strict predication. This much is shown in the fact that Aristotle proceeds to this characterisation after having restricted the discussion to strict predication $^{17}$, and by his introducing in the next lines, as a contrast, predication of accidents ${ }^{18}$ as a second type of strict predication. Accordingly, essential predication is here presented as a sub-type

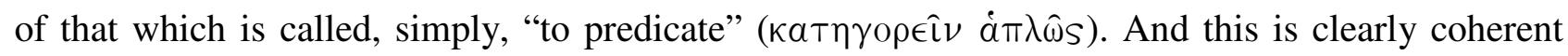
with the fact that predication $\dot{\alpha} \pi \lambda \hat{\omega} s$ abides by the table of categories, wherein the substance (under which essential predicates fall) is merely a category amongst others.

For Aristotle, the question is therefore simple: either there is proper ( $\dot{\alpha} \pi \lambda \hat{\omega} s)$ predication, in which case it abides by the table of categories, where essential predicates are included; or there is no predication at all, unless in a certain accidental sense. When we limit ourselves to predication $\dot{a} \pi \lambda \hat{\omega}$ s, as Aristotle does in the beginning, essential predication comes to be but a kind of strict predication, or, simply put, one kind of predication. In this light, to technically distinguish

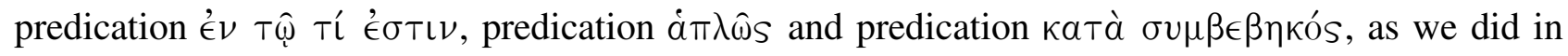
our first table, is to deliberately distance ourselves from the Aristotelian classification. This is because, for Aristotle, either there is or there is not predication. If there is, then predication can as

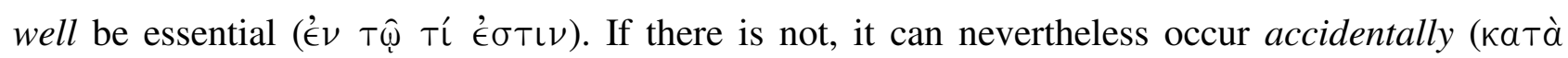
$\sigma v \mu \beta \in \beta \eta \kappa o ́ s)$. In Aristotle's view, the crucial divide stands thus between (strict) predication and accidental predication. In face of this divide, essential predication has virtually no specificity at all (except, of course, to the extent that it is one of the types in which predication is subdivided).

All this appears to definitively establish the third predication table as the correct one from an Aristotelian perspective. However, this is not so. And it is not so precisely because of the passage we are currently commenting. Despite what Aristotle could have, or would have liked to have, expressly acknowledged, this passage sets the grounds for a new account of strict predication, one which opposes not just accidental predication, but also essential predication, or, at least, a certain type of essential predication. It is, therefore, essential predication itself which is, in this clause, implicitly reassessed. This reassessment enables us to understand why essential predication in a

\footnotetext{
17 83a17-23.

18 83a25-35.
} 
Journal of Ancient Philosophy Vol. VI 2012 Issue 2

sense is, and in another sense is not, strict predication and, above all, it enables us to understand in what sense essential predication is, and in what sense it is not, strict predication.

From a general point of view, essential predication is, as already seen, strict predication, for

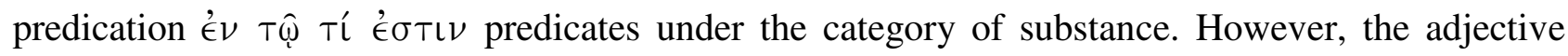
"strict" means here only that essential predication is simply ( $\dot{a} \pi \lambda \hat{\omega} s)$ a type of predication and not a kind of pseudo-predication - a predication "by accident". That said, if we pay close attention to the nature of essential predication, as it is here defined by Aristotle, we realise that there is something fundamental that sets it apart from every other type of predication $\dot{a} \pi \lambda \hat{\omega} s$. In this sense, the term $\dot{a} \pi \lambda \hat{\omega} s$ acquires a new meaning, circumscribing everything that is predication proper, as opposed to accidental "predications" which, due to some motive, are not genuine predications, but also as opposed to essential "predications" which, due to another motive, are not, likewise, genuine predications.

Accidental "predications" are not genuine predications because the sentence's predicate does not express an actual predicate of the subject, i.e., something that truly belongs to it. In Aristotle's terms, in sentences expressing such "predications", the predicate is not attributed to the subject in virtue of the subject being precisely what it is, but because something else (sometimes, the predicate itself) is, accidentally, that subject. Thus, in "The musician is white", it is not because the musician is a musician, but because there is a certain man who happens to be a musician, that the predicate is (accidentally) attributed to the subject. Likewise, in "that white thing is a log", it is not because that white thing is white, but because there is a certain log which happens to be white, that the predicate is (accidentally) attributed to the subject. In this sense, the reason why accidental "predications" are not genuine predications is that one necessary condition of predication is not fulfilled: the predicate is not attributed to the subject because the subject is what it is (or, which is the same, the predicate is not attributed to the subject as something that really belongs to it). In accidental predications, what we see is that, by virtue of a syntactic accident, something that is not a "natural" predicate, or a "natural" subject, shifts, in the sentence, into a logical place that does not "naturally" belong to it.

Now, in the case of essential "predications", this requirement is fulfilled. But, in a way, it is excessively fulfilled, for, in this case, the predicate is not simply attributed to the subject because the subject is precisely what it is, but because the subject is precisely that predicate. Accordingly, whereas in accidental "predications" the predicative link does not truly exist, for the sentence's 
Journal of Ancient Philosophy Vol. VI 2012 Issue 2

predicates are not actual predicates of the subject, in essential "predications", the predicative link is not truly predicative, for the sentence's predicates are not predicates of the subject in the strict sense of the word $(\dot{\alpha} \pi \lambda \hat{\omega} s)$ - they are the subject itself.

In a word, essential "predications" are not, for Aristotle, genuine predications, but identity formulae. They must thus be distinguished from strict predication, just as it happened with accidental "predications", albeit for a different reason. Granted that nowhere in this chapter does Aristotle expressly draw this conclusion. However, in the overall context of his works, this conclusion is required by the characterisation of predication qua attribution "of something to

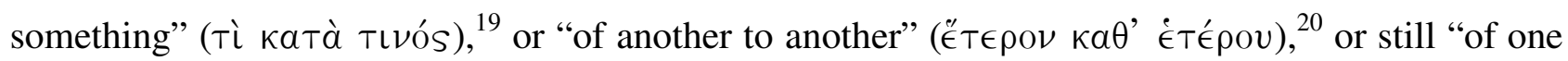
to one" ('€ $\nu \alpha \theta^{\prime} \dot{\epsilon} \nu$ ós), ${ }^{21}$ whereas the attribution of essence is a process "of the same to the same"

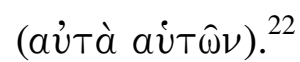

In sum, essential "predication" cannot be strictly considered as predication, in that it is $a$ definition: and a definition does not say something of something, but simply the something; ${ }^{23}$ it does not say of something that [it] is something, but merely what the something is. ${ }^{24}$ It should be noted that the present lesson absolutely concords with the distinction, consistently assumed by Aristotle, in the context of the classification of the principles of demonstration, ${ }^{25}$ between saying

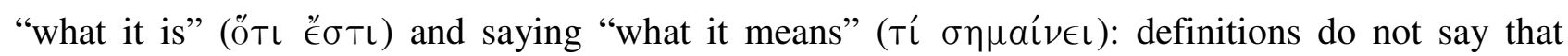
something is something, they merely say what something means. Therefore, only axioms and theses (hypotheses and postulates) are predications - not so definitions. Definitions are not so because they

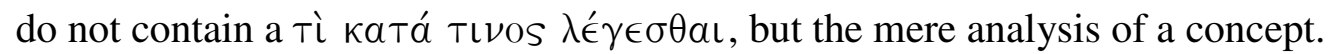

\footnotetext{
${ }^{19}$ Cf. Int. 6, 17a25 (and 3, 16b6-10); APr. I $124 \mathrm{a} 16$.

${ }^{20}$ Cf. Cat. 3, 1 b10.

${ }^{21}$ See, especially, APo. I 22, 83b17-19.

${ }^{22}$ Cf. ibid.

${ }^{23}$ See APo. II 4, 91b1-7 (and $c f .91 \mathrm{a} 15-16$; II 6, 92a6-9; II 13, 96a20-b1); Top. I 5, 102a13-14 (and $c f$. VII 2 , 152b39-153a1); Metaph. Z 4, 1030a7-11.

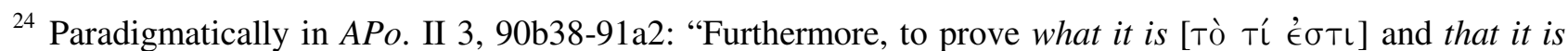

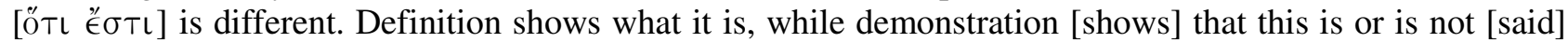

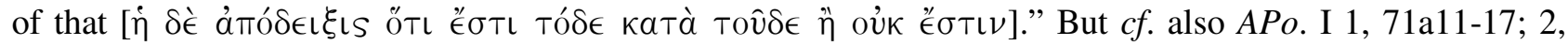
72a18-24; 10, 76b35-77a4.

${ }^{25}$ Cf. APo. I 1, 71a1-17; 2, 72a14-24; 10, 76a31-36.
} 
Journal of Ancient Philosophy Vol. VI 2012 Issue 2

Now, this allows us to understand why is it that essential predication is and is not strict predication and the sense in which it is and the sense in which it is not strict predication. In fact, everything we have developed throughout the present point is valid for definitions only: and what the doctrine introduced in this passage shows exactly is that not every essential predication is a definition. Aristotle distinguishes between essential predicates that mean precisely that of which they are predicated and those that mean a certain type of that of which they are predicated. Let us recall an excerpt already cited: ${ }^{26}$

For instance, when you predicate white of man: man is not precisely white or precisely a certain type of white, but rather animal, since man is precisely an animal.

That is: in the predication "the man is white", subject and predicate are not the same, because the man is not the white, nor a certain type of white (a specific kind of white). But in the predication "man is an animal", subject and predicate are the same, because man is a (certain type of) animal, i.e., a specific kind of animal. In the former predicative sentence, that which is attributed is, therefore, an accident of man (white), whereas the latter attributes that of which man is a species (animal). Now, in general, these two examples outline the distinction between predication of accidents and predication of the substance as types of strict predication. However, if we were to add to them the example Aristotle does not provide in this step, viz., "man is a biped animal", where subject and predicate are the same (for man is precisely what to be a biped animal is) the existence of a further type of "predication" would clearly follow - one that would no longer be strict, but instead more-than-strict (so to speak), or hyperbolic, for here the predicate is precisely the subject.

The difference between the two types of essential predication is clear: in general predication under the category of substance, the subject is not identified with the predicate (man is not animal); instead, it is identified as "a certain type" of the predicate (man is a certain kind of animal). In predication of the essence, on the contrary, the subject is identified with the predicate itself (man is a biped animal); we have here, thus, a definition. In other words, the copulative relation is not, in the latter case, from predicate to subject, rather from definiens to definiendum.

That is why the distinction between the two types of sentence is, from a logical point of view, quite clear too: only the latter is convertible, the former is not. This is precisely what the notion of

${ }^{26} 83 \mathrm{a} 28-30$. 
Journal of Ancient Philosophy Vol. VI 2012 Issue 2

definition as a predication both proper and essential (i.e., where the terms preserve an identity that is at the same time extensional and intensional, comprehending both the objects referred by the concepts and the meaning of the concepts themselves) will technically legislate. ${ }^{27}$ Now, only in the former case, where the predicate says the same as the subject, do we have a definition, where both genus and differentia are attributed to the subject. In the latter case, on the contrary, that which is attributed to the subject is an essential predicate (either the genus or the differentia), but not the whole definiens. Thus, in the former case, the sentence expresses an identity, and is not strictly a

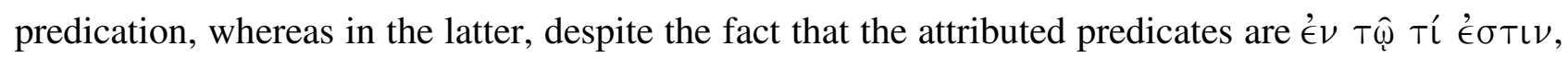
they are not the $\tau i ́$ é $\sigma \tau \iota \nu$ itself, and thus the attribution is operated as a predication stricto sensu

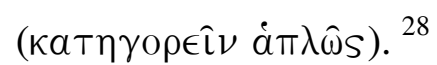

We are now able to establish the sense in which essential predication is and the sense in which it is not strict predication: it is strict predication when that which is attributed is an essential predicate of the subject, but not the complete essence of the subject; it is not strict predication when that which is attributed is the very essence of the subject or, in other words, when it is a definition. One must therefore distinguish between: $(a)$ predication of essence, $(b)$ essential strict predication ("of the substance"), (c) non-essential strict predication ("of accidents") and (d) accidental predication. In face of these elements, it is now possible to revise the Aristotelian table of predication thus:

${ }^{27}$ Cf. APo. II 4, 91a15-16; 6, 92a6-9; 13, 96a20-b1; but especially: Top. I 4, 101b19-23; 6, 102b27-35; 8, 103b6-19; VI 1, 139a31-32; VII 5, 154a37-b12; and passim.

${ }^{28}$ On the distinction between essential predication and predication of the essence (or definition), the clearest passage is perhaps the following: "For if $\mathrm{A}$ is predicable as a mere consequent of $\mathrm{B}$ and $\mathrm{B}$ of $\mathrm{C}$, A will not on that account be the definable form of $\mathrm{C}$ : A will merely be what it was true to say of C. Even if $A$ is predicated

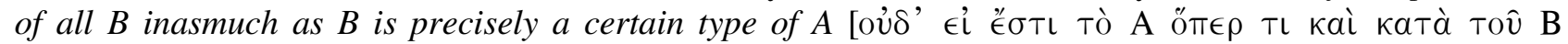

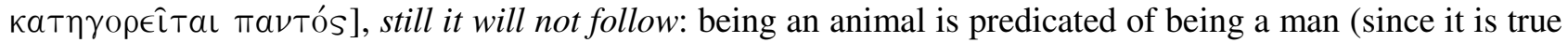
that in all instances to be human is to be animal, just as it is also true that every man is an animal), but not as

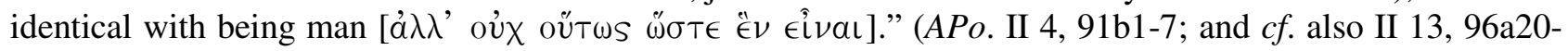
b1) 
Journal of Ancient Philosophy Vol. VI 2012 Issue 2

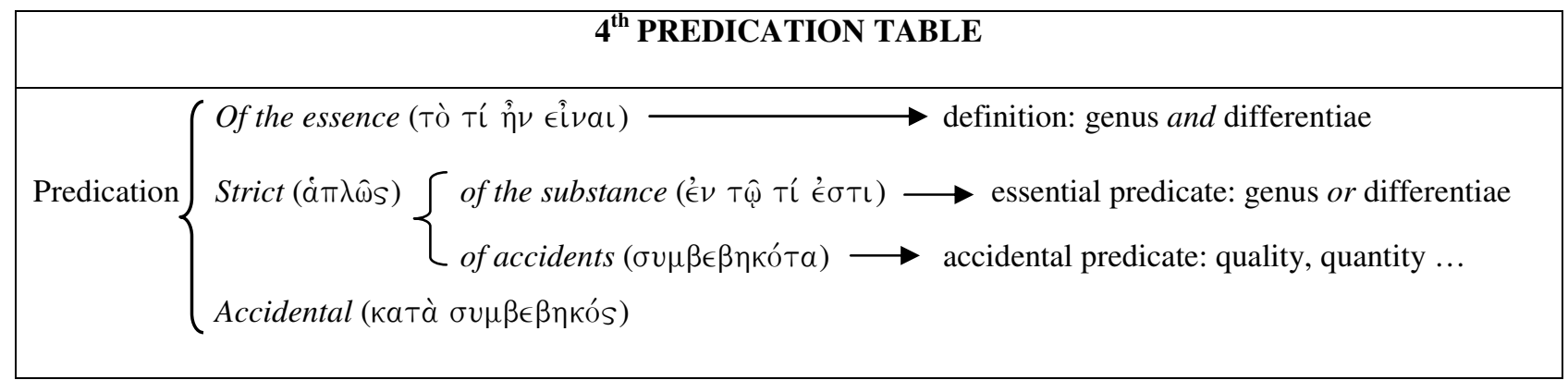

The following observations may be taken as the key of the table, so to speak:

1) Predication of the essence is the statement of the essence of the subject, i.e., the definition. ${ }^{29}$

2) Strict predication is that in which a "natural" predicate is said of a "natural" subject.

3) When the predicate is part of the subject's essence (in other words, when it is a predicate under the category of substance), the case is one of strict predication of the substance.

4) When the predicate is a simple accidental predicate of subject (alternatively, when it is a predicate under a category other than that of substance), the case is one of predication of the accident.

5) Accidental predication is that in which predication proceeds in a "counternatural" way either because $[a]$, in a sentence, an accident is attributed to another accident ("The musician is white"), or because $[b]$, in a sentence, a substance is attributed to an accident ("that white thing is a log").

As we shall see, the next text will provide us with elements to fine-tune this terminology and to adapt it in accordance with the Aristotelian table of predication.

\section{A preliminary account}

Before moving forwards, though, let us see how these data and those that follow from the previous paragraph enable us to adjust and improve the classification of predication types implicitly

\footnotetext{
${ }^{29}$ Top. I 5, 101b38. Cf. APo. II 3, 90b29-33; Top. I 4, 101b17-23; 8, 103b6-12; V 2, 130b25-28; 3, $131 \mathrm{~b} 37-$ 132a9; VII 3, 153a6-22; 5, 154a23-32; 155a18-22; Metaph. $\Delta$ 8, 1017b21-22; Z 4, 1030a2-b13; 5, 1031a114; 13, 1039a19-20; and also APo. I 22, 82b37-83a1; II 3, 90b3-4; Top. I 6, 102b27-35; I 18, 108a38-b6; V 5, 135a9-12; VI 4, 141a26-b2; 141b15-34; Metaph. B 3, 998b4-8.
} 
Journal of Ancient Philosophy Vol. VI 2012 Issue 2

addressed in this chapter of the Posterior Analytics. After those paragraphs where he distinguished accidental predication from strict predication, restricted the investigation to the latter and brought back that which can be predicated under the scope of the table of categories, Aristotle advances two steps in this paragraph: on the one hand, he integrates predicates under the category of substance in predication $\dot{\alpha} \pi \lambda \hat{\omega} s$; on the other, he reintroduces the notion of accident, with a new purpose, viz., not as means to discriminate between types of predication, but to designate one of the predicate classes that, together with those that fall under the category of substance, will exhaust the entirety of what can be strictly predicated. ${ }^{30}$

Taken together, the two newly integrated elements do not add new types of predication to the already established ones. What they do bring is a further characterisation of the types in which strict predication is subdivided: the predication of substance, on the one hand, and the predication of accidents, on the other. However, the simple fact that Aristotle makes here explicit that predication of accidents is a kind of strict predication is, in itself, significant in another regard. By doing so, the

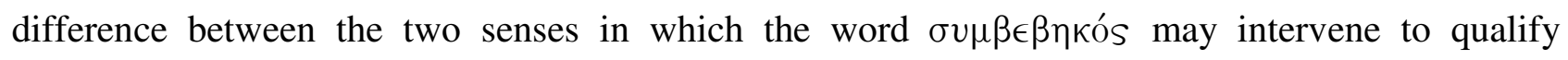
predication is conclusively rendered clear: in one of those senses, it determines accidental predication, which is accidental insofar as it is not predication except by accident (кaTà $\sigma v \mu \beta \in \beta \eta \kappa o ́ s$, per accidens); in the other, quite distinct, sense, it delimits predication of accidents, which is predication stricto sensu ( $\dot{\alpha} \pi \lambda \omega \hat{s})$, although that which is given through it as predicates of

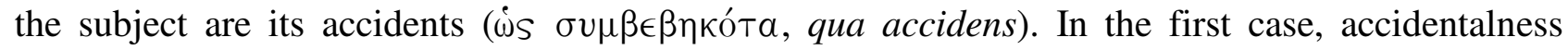
qualifies the very predication: and, via this qualificative, such "predication" stands excluded from the set of strict predication. In the second case, accidentalness qualifies but the predicate: therefore, the genuine character of the predication is not affected. In the first case, accidentalness has a methodological sense and its task is to keep seemingly predicative formulae from the strict domain of predication. In the second case, it bears ontological value and its task is to discriminate a certain type of predicate that has legitimate place in strict predication. Retrospectively, it is not immaterial that, when distinguishing between accidental predication and strict predication, Aristotle never fails

\footnotetext{
${ }^{30}$ For which reason, as aptly noted by Ross, "the predication of $\sigma v \mu \beta \in \beta \eta \kappa o ́ T \alpha$ is of course to be

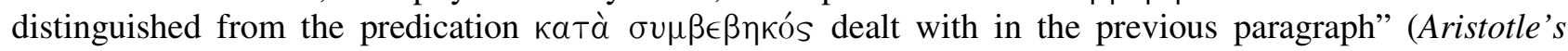
Prior and Posterior Analytics, p. 577).
} 
Journal of Ancient Philosophy Vol. VI 2012 Issue 2

to mention predication of accidents as an instance of strict predication: ${ }^{31}$ for that means that, in the distinction between (strict) predication and mere accidental predication, a further distinction, viz., between predication of accidents and accidental predication, is also being established. ${ }^{32}$

This is, of course, a particularly important point of the present text. At the same time, though, and as we have just seen in considerable detail, the paragraph also suggests another relevant aspect: by virtue of its very structure, predication of the substance would be better characterised if we allow it to be distinguished further, between predication of the essence (which is not, strictly speaking, predication, and should therefore be treated separately, viz., as definition) and predication of that which "is in the essence", namely, the genus or the differentia (which is, from a logical standpoint, strict predication - albeit with unique features - and can thus be considered as a subtype of predication $\dot{\alpha} \pi \lambda \hat{\omega} s$, viz., essential predication).

One final observation. Obviously enough, the notion of substance sanctions two different meanings in this context: one, the category under which the substance is predicated (i.e., predication of genera or of differentiae); the other, the "natural" subject which, in one of the accidental predication modalities, is shifted to the predicate's logical slot. In neither of these senses, however, is the substance itself a predicate: in the former case, it stands as a category of predicates (the genera and differentiae said of subjects); in the latter, it is a substance stricto sensu, therefore necessarily a subject that only by accident comes to fill the predicate's logical slot. One should note at this point that Aristotle does not clarify $[a]$ whether "substance" should be here interpreted as concerning primary substances (in the sense of the Categories) only, both primary and secondary substances, or, in general, any subject exhibiting the logical behaviour of a substance, ${ }^{33}$ and $[b]$ whether one should take "predicates under the category of substance" to mean those genera and differences said of primary substances only, or these plus those said of secondary substances, or, in

\footnotetext{
31 "We can affirm without falsehood that the white (thing) is walking and that that big (thing) is a log; or again, that the $\log$ is big and that the man walks. But the affirmation differs in the two cases. When I affirm that the white is a log, I mean that something which happens to be white is a log, not that white is the subject in which log inheres ..." (APo. I 22, 83a1-7)

${ }^{32}$ The most paradigmatic case is to be found in APo. I 19, 81b25-29: "Here is what I mean by 'accidental': when we say, for instance, that that white thing is a man we are not saying the same thing as when we say that the man is white, since the man is not white because he is something else, while the white thing [is a man] because the white is, for man, an accident."
}

${ }^{33}$ Cf. Metaph. Z 1, 1028a36-b2; 4, 1030a17-27. 
Journal of Ancient Philosophy Vol. VI 2012 Issue 2

general, genera and differences of any subject exhibiting the logical behaviour of a substance. ${ }^{34}$ This question could have three different answers, depending on the dominion it concerns. In the context of the discussion motivating these developments (viz., the possibility of demonstrations having an infinite number of premises), the appropriate response would be the most restrictive, for the purpose would be that of guaranteeing that the series of subjects stops at individuals (and the series of predicates at categories). In the wider context of Posterior Analytics, the convenient answer would be either of intermediate restrictiveness or the broadest possible, in that demonstrations typically deal with universals, for which reason both predicates and subjects should be universal. Generally speaking, nothing militates against choosing the broadest answer; on the contrary, everything points towards it being the favoured one.

\section{Predication of Accidents (a) Per Se and (b) Not Per Se}

Text: ${ }^{35}$

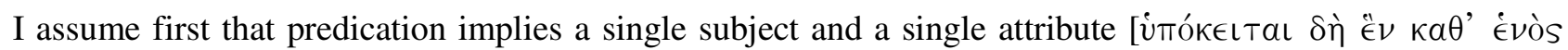
$\kappa \alpha \tau \eta \gamma о \rho \in \hat{\imath} \sigma \theta a \mathrm{l}]$ and secondly that, in the case of non-essential predication, the same things are not

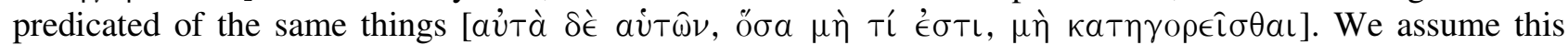

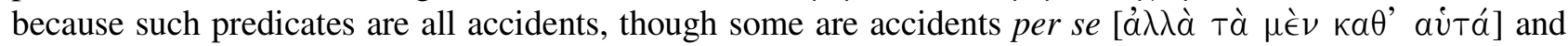

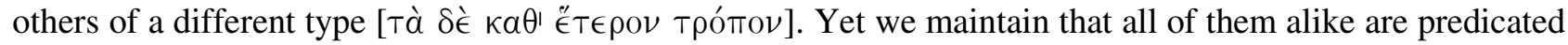
of some subject and that an accident is never a subject, since we do not class anything as accident except

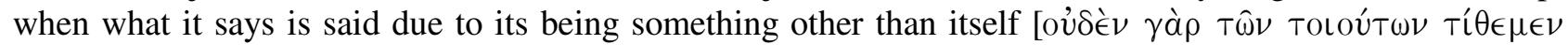

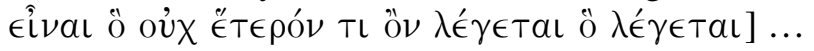

\section{Comment:}

We introduce now the last remaining element that allows us to complete the Aristotelian classification of predication: the distinction between accidents per se and "simple" accidents. ${ }^{36}$ We may reformulate the corresponding table thus:

\footnotetext{
${ }^{34}$ Cf. Top. I 9, 103b27-39; Metaph. Z 1, 1028a36-b2; 4, 1030a17-27.

${ }^{35}$ APo. I 22, 83b17-23.

${ }^{36} C f$. in this regard Metaph. $\Delta$ 30, 1025a30-34. Other occurrences, both explicit and implicit, of

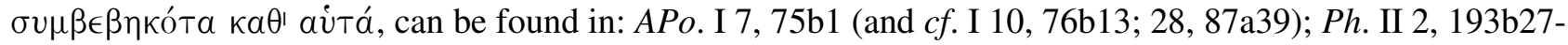
28, and III 4, $203 \mathrm{~b} 33$ (and $c f$. De an. I 1, 402a7; 402a15; 402b18; 402b21; 402b23-24; 402b26-403a1; 5, 409b14); PA I 3, 643a27-28 (and $c f$. I 1, 639a18-19; 639a26; 641a24-25); PA I 5, 645b1-3 (and $c f$. HA I 6, 491a9-11; MA 1, 698a1-4); Metaph. B 1, 995b20; 995b25-26; 2, 997a20; 997a21-22 (and cf. Metaph. 997a25-34; Г 1, 1003a21-22; 2, 1005a13-14; E 1, 1025a10-13; 1026a31-32; K 3, 1061b4-6); M 3, 1078a5-6.
} 
Journal of Ancient Philosophy Vol. VI 2012 Issue 2

\begin{tabular}{|c|c|c|}
\hline \multicolumn{3}{|c|}{$5^{\text {th }}$ PREDICATION TABLE } \\
\hline Predication & 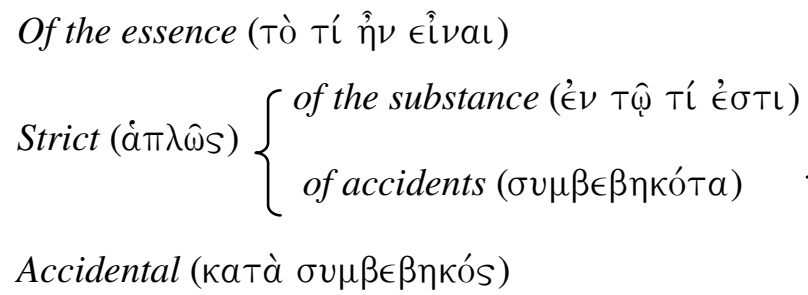 & 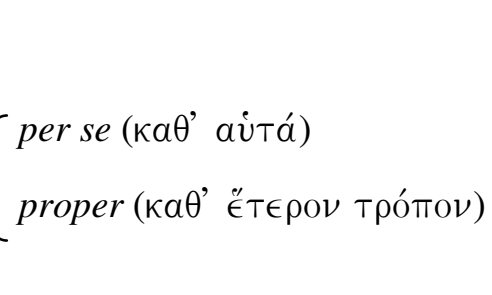 \\
\hline
\end{tabular}

Some final observations in this regard:

1) Predication stricto sensu is that which is neither accidental predication nor predication of the essence.

2) It corresponds to three types: [i] predication of genus or differences; [ii] predication of accidents per se; [iii] predication of "simple" accidents.

3) "Predication" of the essence is not, in fact, predication, rather an identity formula, in the terms previously mentioned.

4) Accidental "predication" is predication only equivocally: in fact, it occurs only when, by virtue of a grammatical accident, the ontological subject of the attribution slides into the predicate's syntactic slot, which is not naturally its own, so that, in the sentence, there is no actual restitution of any genuine predication.

\section{In defence of Aristotle: No Individual Can Be a Predicate}

This Aristotelian thesis, which although metaphysical in nature is, as seen throughout the current essay, indissociable from Aristotle's doctrine on predication, was modernly challenged by several authorities. Amongst the classic moments, it is worth highlighting those produced during the 
Journal of Ancient Philosophy Vol. VI 2012 Issue 2

earlier decades of the $20^{\text {th }}$ century by Frank Plumpton Ramsey, ${ }^{37}$ John Cook Wilson, ${ }^{38}$ Jan Lukasiewicz $^{39}$ and Peter Strawson. ${ }^{40}$ On this particular issue, the work of Cook Wilson is somewhat collateral, since it attempts to present a general doctrine on the nature of the subject and only marginally crosses paths with Aristotle's. ${ }^{41}$ Strawson's essays, in turn, are, to a considerable extent, a recovery of the analysis developed by Ramsey, with whom he would come to part ways later, ${ }^{42}$ for which reason it is preferable to resort to the original directly. ${ }^{43} \mathrm{We}$ are thus left with Ramsey and Lukasiewicz, to whom we now turn our attention.

The object of Ramsey's essay is to show that "the whole theory of particulars and universals is due to mistaking for a fundamental characteristic of reality what is merely a characteristic of language". ${ }^{44}$ To that effect, he attempts to show that "there is no essential distinction between the subject of a proposition and its predicate", hence "no fundamental classification of objects can be based upon such a distinction". ${ }^{45}$ Ramsey's argument can be schematically presented thus:

1. "Socrates is wise" and "Wisdom is a characteristic of Socrates" express the same proposition. ${ }^{46}$

2. However, that which is subject in one is predicate in the other, and vice-versa.

37 "Universals", Mind, 34, 1925 (reedited, with an appendix from 1926, in: The Foundations of Mathematics and other Logical Essays, pp. 112-134, 135-137, from which our quotations are taken).

38 Statement and Inference, I-II, Oxford, Clarendon Press, 1926.

${ }^{39}$ Aristotle's Syllogistic from the Standpoint of Modern Formal Logic, Oxford, Oxford University Press, $1957^{2}$ (we translate from the French edition: Paris, Librairie Armand Collin, 1972).

${ }^{40}$ Successively in: "On Particular and General", Proceedings of the Aristotelian Society, 54, 1953/1954, pp. 233-261; "Logical Subjects and Physical Objects", Philosophy and Phenomenological Research, 17, 1957, pp. 441-457; "Logical Subjects and Physical Objects. A reply to Mr. Sellars", Philosophy and Phenomenological Research, 17, 1957, pp. 473-477.

${ }^{41}$ In the terms of that doctrine, a subject is that of which a sentence asserts something, which, depending on the context, may or may not coincide with the grammatical subject and, in general, with the nominal component that integrates the sentence.

${ }^{42}$ Cf. Individuals, pp. 177-179 e 237.

${ }^{43}$ For pertinent criticism on Strawson's primitive position, see Sellars, "Logical Subjects and Physical Objects", and Baylis, "Logical Subjects and Physical Objects. Comments".

44 "Universals", Foundations of Mathematics, p. 117.

${ }^{45}$ Op. cit., p. 116.

${ }^{46}$ In Strawson, who renovates, although more timidly, Ramsey's argument, the typical example is "All Socrates' virtues were possessed by Plato" ( $c f$. "Logical Subjects and Physical Objects", pp. 446-449). 
Journal of Ancient Philosophy Vol. VI 2012 Issue 2

3. Now, given that any predicative sentence can be analogously converted into an equivalent sentence where subject and predicate switch places, it follows that "there is no essential distinction between the subject of a proposition and its predicate". $Q E D$

The argument would be persuasive if the second premise were true. As it happens, it is not. In fact, the first sentence's predicate is the second sentence's subject, but the first sentence's subject $i s$ not the predicate of the second. "Socrates" is the subject of the first sentence; but the predicate of the second sentence is not Socrates, it is "a characteristic of Socrates". ${ }^{47}$ Thus, Ramsey only showed something we already knew, at least since Aristotle: that everything that can be a predicate in a sentence can be a subject in another. He did not show, however, what he intended to show: that if it can be a subject in a sentence, then it can be a predicate in another. The Aristotelian irreducibility of the individual as ultimate subject remains thus unscathed.

But there is more. The second premise involves a fatal ambiguity. When we say "that which is subject in one, is predicate in the other, and vice-versa", the phrases "in one" and "in the other" indicate different things depending on whether they refer, in Ramsey's terms, the sentence or the proposition. ${ }^{48}$ The point is that, if one adopts, as does Ramsey, the distinction between sentence and proposition, one assumes that the latter is relatively independent from the former, particularly in view of the fact that it is precisely in order to safeguard the inalterability of the proposition against formal variations that affect the sentence that the distinction itself is put forward. As such, switching the position of the terms within the sentence will not necessarily entail an equivalent permutation in the proposition it expresses, if it is the case, as it is here, that the fact asserted by the proposition remains essentially unchanged when the switch takes place in the sentence. Given that

\footnotetext{
${ }^{47}$ Sellars, too, points out, not only against Strawson, but directly against Ramsey, that in "Wisdom is instantiated by Socrates", the predicate is not "Socrates", rather "to be instantiated by Socrates" (cf. "Logical Subjects and Physical Objects", p. 470).

${ }^{48}$ The distinction between "proposition", the assertive content of a sentence, and "sentence", the proposition's material support, can be considered an indissociable topic from essentialism in all its forms, already present in Aristotle, as we had occasion to show in "Ciência e Opinião em Aristóteles" (Aspectos Disputados da Filosofia Aristotélica, pp. 259-278), and, as we can see, also assumed by Ramsey. Quine made it an irreparably controversial issue; see, especially, "Ontological Remarks on the Propositional Calculus" (1934); "Speaking of Objects" (1958), pp. 21-25; Word and Object (1960), §§ 40-43; "Propositional Objects" (1968), pp. 139-144; Philosophy of Logic (1970), pp. 1-14; The Roots of Reference (1974), § 9, p. 36; Pursuit of Truth $\left(1992^{2}\right)$, pp. 52-53, 77-79, 102; From Stimulus to Science (1995), pp. $77-$ 78.
} 
Journal of Ancient Philosophy Vol. VI 2012 Issue 2

the sentences "Socrates is wise" and "Wisdom is a characteristic of Socrates" express, according to Ramsey, the same proposition, the relation either sentence represents (the fact either sentence asserts, as Ramsey would put it) is the same: the relation of a predicate (wisdom) to a subject (Socrates) - a relation that holds regardless of how the proposition is grammatically transcribed, i.e., whichever term ("Socrates" or "wisdom") happens to be the grammatical subject of the sentence. Now, there are two important things here. First, when we move from the sentence to the proposition, we realise that the subject is always the same - Socrates. That is, at the propositional level (which is to say, at the level of the relation represented by the sentence), the subject is, necessarily, the ultimate subject, i.e., the individual. Second, this is precisely why the propositional subject of a sentence "A is B" resists, by nature, being converted into a grammatical predicate; it can but integrate, as in the case of Ramsey's example, the grammatical predicate of the converse sentence, which asserts that B is a characteristic of A (or that B pertains to A, or that B is said of A, etc.), i.e., which precisely asserts $\mathrm{B}$ as the predicate of $\mathrm{A}$.

We can now turn to Lukasiewicz. Commenting on a passage from Prior Analytics, he says: ${ }^{49}$

This passage $e^{50}$ contains some inaccuracies that it would be best to correct before going any further. It is wrong to say that one thing can be predicated by another; a predicate is part of a proposition, ${ }^{51}$ and a proposition consists in a series of uttered or written terms, which possess a certain meaning; therefore, one cannot predicate things: one can predicate the word "Callias" by another word: one cannot predicate Callias himself. The above classification does not concern things - it concerns terms.

The reader who has followed our study thus far, or already possesses some knowledge, even if elementary, of Aristotelian thought, will realise that this whole excerpt is built upon a misunderstanding concerning two levels that Aristotle keeps quite apart: the ontological level, where we speak of predicates as something that pertains to things; and the logical level, where we speak of predicates as something that is said of things (through the terms by which things are referred). In the latter case, the predicate is in fact a term and it is in fact part of a sentence; in the former, however, the predicate is an entity and, as such, it is utterly extra-logical and extralinguistic. The entire Aristotelian system of categories (the ways according to which something is said to be) can only make sense assuming this presupposition.

\footnotetext{
${ }^{49}$ La syllogistique d'Aristote, p. 26.

${ }^{50}$ APr. I 27, 43a25-43.

51 "Proposition", in this context, has, of course, the same meaning as "sentence".
} 
Journal of Ancient Philosophy Vol. VI 2012 Issue 2

More than that: the two levels are connected - and they are connected by the primacy of the former over the latter. In fact, it is only because something pertains to something else qua an ontological predicate that it can be said of that thing as a logical predicate. It is only insofar as something is a predicate of something that it can become that which is predicated of that thing in a sentence (in the latter case, subject and predicate are not, of course, the entities themselves, rather the terms that refer to those entities). ${ }^{52}$ In this sense, Aristotle never states or implies that "one thing can be predicated by another": what he does say is that "something" (i.e., an entity, in general terms) can be a predicate of another. He certainly states and implies, however, that "things can be predicated": for, although the subject of a predicative sentence is not the thing itself, it is the thing itself that, through its name, is predicated by the predicate of the predicative sentence. ${ }^{53}$ On our subject, Lukasiewicz adds: ${ }^{54}$

Likewise, it is wrong to say that individual or singular terms, e.g., "Callias", cannot be truly predicated of anything. Aristotle himself is the first to line up examples of true propositions with singular predicates: "This white object is Socrates"; or "That who approaches is Callias". These propositions are true, he says, "by accident", ${ }^{55}$ but there are other examples of the same kind which truth is not purely accidental, such as "Socrates is Socrates" or "Sophroniscus was Socrates' father".

The negligence that this excerpt exhibits as to the Aristotelian doctrine that we have been analysing is disturbing. In fact, not only does the excerpt fully depend on the misconception just detected, for the notion of predication lies, as we saw, upon an ontological distinction that

\footnotetext{
${ }^{52}$ On the problem of accidental predication, Lear sees, correctly, the juxtaposition of two levels - logical and ontological - in all predication. Cf. Aristotle and Logical Theory, p. 31: "A phrase like 'the white thing is a log' is a degenerate form of predication, for it fails to reveal the metaphysical structure of subject and predicate. It is not that the white thing is the underlying subject which happens to be a log. Rather the log is the underlying subject which happens to be white (An. Post. 83a1-14). Only predications which reveal metaphysical structure are strict and it is with these that proof is concerned." And a few lines ahead: "Aristotle distinguishes predicating from saying truly (An. Post. 83a38). Predication is not merely a linguistic act. Though one can say both 'the white thing is a log' and 'the log is white', only the latter is a genuine predication."

${ }^{53}$ In fact, even from the point of view of modern elementary logic, what does it mean to say that an object satisfies a predicate, other than that object has the property signified by the predicate and, consequently, that the predicate is predicated of it? Here is a point concerning which there has been a rather unjustified desire to draw distinctions between the assumptions of modern logic and those of Aristotelian logic.

${ }^{54}$ Op. and loc. cit.

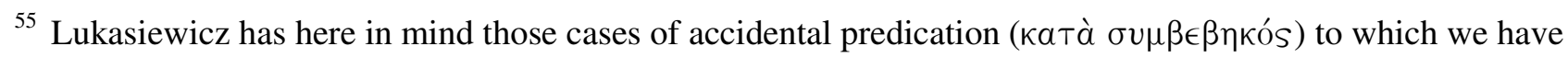
made abundant reference in the text.
} 
Journal of Ancient Philosophy Vol. VI 2012 Issue 2

Lukasiewicz misses entirely, it also is wholly underpinned by four examples, none of which is an instance of predication, due to the exact reasons that our preceding analysis has made clear. This is evident in the case of the first two examples, taken from the Prior Analytics chapter under debate, for they correspond precisely to the examples given for accidental predication. In "that white object is Socrates", as well as in "that who approaches is Callias", "Socrates" and "Callias" are not predicates of "that white object" and "that who approaches", respectively; rather, they are their corresponding names. The sentence is, consequently, an identity formula - not a predication. ${ }^{56}$

As to the third example, "Socrates is Socrates", we do not see here how the second "Socrates" could be a predicate of the first. Why is the second Socrates said of the first and not the other way around? Could the author be suggesting that it is the order of the sentence that determines the predicate of the attribution? But then, if one says "Socrates was a great philosopher", "Socrates" is the subject, yet if one says "A great philosopher was Socrates", "Socrates" becomes the predicate? It is not, evidently, the order of the sentence that determines the predicate of the attribution. And it is also clear that the first and the second "Socrates" in the sentence "Socrates is Socrates" are undistinguishable as subject and predicate, which means, in other words, that the sentence does not express a predication.

The fourth example is the most surprising. How does Lukasiewicz interpret the clause "Socrates' father" in the sentence "Sophroniscus was Socrates' father"? As a singular term? But, if it is a singular term, then it is either a name or a definite description: and, in both cases, not a predicate. Conversely, if it is a predicate (the predicate " $x$ is Socrates' father"), then it is not a singular term: it is the expression of a property that can be satisfied by objects designated by certain singular terms. In the first case, we have no "individual or singular term", in Lukasiewicz words, as predicate; in the second, the predicate is not an "individual or singular term". In both cases, the example does not demonstrate what Lukasiewicz intended it to demonstrate. The crucial point here is that Lukasiewicz's whole reasoning misses - fundamentally - the Aristotelian doctrine in question. What Aristotle implies in the notion of accidental predication is the ontological thesis

\footnotetext{
${ }^{56} C f$., along the same line, R. Smith, "Logic", p. 33: "But when we force 'Socrates' into predicate position, what we have no longer seems to be predication, but instead a kind of identification: 'That man is Socrates' amounts to 'That man and Socrates are the same'."
} 
Journal of Ancient Philosophy Vol. VI 2012 Issue 2

according to which an individual cannot be predicated of another. It is not a question of terms or linguistic predicates: it is a question of real things and actual predicates.

Now, thus understood, the doctrine is clear as to all the examples given: the individual Socrates is not a predicate of that white blotch that I see over there; rather, white is a predicate of the individual Socrates. And it is only by virtue of a linguistic accident that we can incorrectly express this truth, saying "that white thing is Socrates". From a logical point of view, the ontological notion of accidental predication means, thus, the following: the subject of the sentence shifts, by linguistic accident, into the predicate's slot. And this entails, in the terms above mentioned, a more fundamental idea: the sentence "that white thing is Socrates" expresses the proposition "Socrates is white". (Naturally, the same is valid in the sentence "that who approaches is Callias" and other similar sentences.)

In the remaining examples, which are not instances of accidental predication, the ontological thesis according to which no individual can be a predicate is also not undermined. In fact, all these (and the same would hold for the previous examples, which can be likewise interpreted) are cases of identity, not predication, and thus none exhibits individuals qua predicates. Alternatively, one would have to admit that, in sentences like "Sophroniscus was Socrates' father", the predicate ("Socrates' father") is not a singular term, but a general term (" $x$ is the father of Socrates"), in which case the Aristotelian thesis is, once again, not affected.

\section{Final Discussion and Conclusions}

The Aristotelian notion of accidental predication appeals, first of all, to a question of purely ontological character - one which is crucial to acknowledge as such, in order to avoid mistaking it with the related logical question. The ontological issue is thus: there are certain realities that, due to their very nature, cannot be predicates of anything. Lukasiewicz saw fit to correct Aristotle, recalling that only terms - not realities - can be predicates. But this only manifests the confusion as to the two levels. In Aristotle's thought, a predicate is one thing and that which is predicated (viz., in the predicative sentence) is a whole other thing. Predicate is an ontological notion, and it has to do with that which belongs to a given thing (thus called, in equally ontological manner, its subject). That which is predicated is a logical notion, strictly dependent from the ontological notion, and it 
Journal of Ancient Philosophy Vol. VI 2012 Issue 2

has to do with what can be said of the subject (in a predicative sentence). In a predicative sentence, that which is predicated is, of course, a term. But this term can always be predicated of another, because what it designates is a predicate of that which is designated by the other.

Now, there are things that cannot be (ontological) predicates of anything - such is the case of individuals. Accordingly, if the name of one of those things (i.e., a singular term) comes to be a parte of a predicative sentence, filling the predicate's slot, there we have, literally, an accident. But do such cases really exist? Surely not in Aristotle's examples ("The musician is white", "that white thing is a log"): in his examples, what fills the predicate's slot is never a singular term. But, for the sake of the argument, one could re-read the examples in Lukasiewicz's vein ("this white object is Socrates", "that who approaches is Callias"), where the predicate is, surely enough, a singular term.

Before this situation, we are forced to reiterate: only accidentally can a name (a singular term) appear as a predicate in a predicative sentence, since the individual to which that name corresponds is not the actual predicate of the thing referred by the term appearing as subject in the sentence, as it is patently shown in Aristotle's examples, and in Lukasiewicz's, for that matter, and well explainable in light of the Aristotelian doctrine. Now, that accident by which the name of something that cannot be a (ontological) predicate appears as (logical) predicate is, quite clearly, an accident of linguistic nature. This is what Aristotle is saying when he states that the sentence "this white thing is a log" is an inversion of the true predication "the log is white". And this is also the notion present in the neo-Platonic distinction between "natural" predication and "counternatural" predication. It is in this case, and in this case only, that the second level - the logical plan - intervenes.

One could argue that, from a logical standpoint, the distinction between natural and counternatural predication (an ontological distinction) is meaningless and, thus, that it is meaningless to say that the "real" subject of the proposition expressed by the sentence "this white thing is a log" is that which is represented, in the sentence, by the predicate. From a strictly logical point of view, "log" is said of "this white thing" and is, therefore, the sentence's predicate. As to those ontological claims according to which, in the order of reality, it is white which is the predicate of $\log$, and not the other way around, logic may very well respect them, but it is under no obligation to take them into consideration. However, if this were the case, in order to accommodate in extremis Aristotle's thesis, it would be necessary to concede that, although the objects it designates could never be (ontological) predicates, singular terms themselves could, indeed, be (logical) predicates. 
Journal of Ancient Philosophy Vol. VI 2012 Issue 2

As it happens, this is not so. First of all, an Aristotelian could always argue that logic does not deal with sentences; it deals with propositions, where a singular term is never a predicate (except, of course, in identity formulae). Proposition, the last stronghold of essentialism, is also the last stronghold of metaphysics; and in the intensional dwelling of propositions, the ontological order of reality can always be preserved. Secondly, Aristotle would still have good reasons to maintain that, even from a logical standpoint, singular terms cannot be predicates.

Why? Because in every situation where accidental predication occurs, either the predicate is not an actual singular term, or the case is not one of predication. In "this white thing is a log" (a typical example in Aristotle), "a log" most certainly is not a singular term - it is a general one. What the sentence means to express is that it happens to this white thing (singular) to belong to the class (universal) of logs. To be perfectly fair to Aristotle, one should have put it vice-versa, but, for our purposes, the warning will suffice. No doubt this sentence, and every sentence equivalent to it, can always be read placing a singular term in the predicate's position. In such case, it would read something like "this white thing is this log" - graceless equivalent of "this white thing is Socrates" or "that there is Callias". But then, "this log", or "Socrates", or "Callias", is not attributed to "this white thing" as predicate, rather as another name for "this white thing", in which case the sentence is not asserting predication, but indeed identity, between the two terms. In this case, Aristotle's accidental predication would be assimilated into the second class of Lukasiewicz's examples. In other words, Aristotle's accidental predication would be systematically reinterpreted as an illformed (or "accidental") identity formula. It is, to be sure, a somewhat far-fetched hypothesis. Yet, it holds a certain appeal, for it would allow us to reunite anew the two fringes, "lower" and "upper", of Aristotle's predication.

António Pedro Mesquita

Universidade de Lisboa 
Journal of Ancient Philosophy Vol. VI 2012 Issue 2

References

BARNES, J. (trad.), Posterior Analytics, Oxford, Clarendon Press, 1992.

BAYLIS, C. A., "Logical Subjects and Physical Objects. Comments", Philosophy and Phenomenological Research, 17 1957, pp. 483-487.

BONITZ, H., Index Aristotelicus, Aristotelis Opera. Editio altera, ed. I. Bekker, revis. O. Gigon, V, Berlin, Königlichen Preussischen Akademie der Wissenschaften, 1961.

COOK WILSON, J., Statement and Inference, I-II, Oxford, Clarendon Press, 1926.

LEAR, J., Aristotle and Logical Theory, Cambridge, Cambridge University Press, 1980.

LUKASIEWICZ, J., Aristotle's Syllogistic from the Standpoint of Modern Formal Logic, Oxford, Oxford University Press, 19572 (french edition: trad. F. Caujolle-Zaslawsky, Paris, Librairie Armand Collin, 1972).

MESQUITA, A. P., Aspectos Disputados da Filosofia Aristotélica, Lisboa, INCM, 2004.

MESQUITA, A. P., Obras Completas de Aristóteles. I 1: Introdução Geral, Lisboa, INCM, 2005.

MURE, G. R. G. (trad.), The Works of Aristotle translated into English, I, Oxford, Clarendon Press, 1908.

QUINE, W. van O., From Stimulus to Science, Cambridge (Mass.) - London, Harvard University Press, 1995.

QUINE, W. van O., "Ontological Remarks on the Propositional Calculus”, Mind, 43, 1934, pp. 472476 (reedited in: The Ways of Paradox and Other Essays, Cambridge (Mass.) - London, Harvard University Press, 19977, pp. 265-271).

QUINE, W. van O., Philosophy of Logic, Englewood Cliffs (N. J.), Prentice Hall, 1970.

QUINE, W. van O., "Propositional Objects", Crítica, 2, 1968, pp. 3-22 (reedited in: Ontological Relativity and Other Essays, New York, Columbia University Press, 1969, pp. 139-160).

QUINE, W. van O., Pursuit of Truth, Cambridge (Mass.) - London, Harvard University Press, 19922.

QUINE, W. van O., The Roots of Reference, LaSalle (Ill.), Open Court, 1974.

QUINE, W. van O., "Speaking of Objects", Proceedings and Addresses of the American Philosophical Association, 31, 1958, pp. 5-22 (reedited in: Ontological Relativity and Other Essays, New York, Columbia University Press, 1969, pp. 1-25).

QUINE, W. van O., Word and Object, Cambridge, MIT Press, 1960.

RAMSEY, F. P., "Universals", Mind, 34, 1925 (reedited, with an 1926 appendix, in: The Foundations of Mathematics and other Logical Essays, ed. R. B. Braithwaite, pref. G. E. Moore, London, Kegan Paul, Trench, Trubner \& Co., 1931, pp. 112-134, 135-137).

ROSS, W. D. (ed.), Aristotle's Prior and Posterior Analytics. A Revised Text with Introduction and Commentary, Oxford, Clarendon Press, 1949. 
Journal of Ancient Philosophy Vol. VI 2012 Issue 2

SELLARS, W., "Logical Subjects and Physical Objects", Philosophy and Phenomenological Research, 17, 1957, pp. 458-472.

SMITH, R., "Logic", The Cambridge Companion to Aristotle, ed. J. Barnes, Cambridge, Cambridge University Press, 1995, pp. 27-65.

SMITH, R. (trad.), Topics Books I and VIII, Oxford, Clarendon Press, 1994.

STRAWSON, P.-F., Individuals - An Essay in Descriptive Metaphysics, London, Methuen, 1959.

STRAWSON, P.-F., "Logical Subjects and Physical Objects", Philosophy and Phenomenological Research, 17, 1957, pp. 441-457.

STRAWSON, P.-F., "Logical Subjects and Physical Objects. A reply to Mr. Sellars", Philosophy and Phenomenological Research, 17, 1957, pp. 473-477.

STRAWSON, P.-F., "On Particular and General”, Proceedings of the Aristotelian Society, 54, 1953/1954, pp. 233-261 (reedited in: The Problem of Universals, ed. C. Landesman, New York, Basic Books, 1971, pp. 131-149).

TREDENNICK, H. (ed.), Aristotle, II, London, Loeb Classical Library, 1989.

TRICOT, J. (trad.), Organon. IV: Les secondes analytiques, Paris, Vrin, 1965.

WAITZ, T. (ed.), Aristotelis Organon graece, I-II, Lipsiae, sumptibus Hahnii, 1844-1846.

WALlIES, M., Commentaria in Aristotelem graeca, edita consilio et auctoritate Academiae Litterarum Regiae Borussicae, XIII.3, Berlin, G. Reimer, 1960. 